\section{Spectrum of Contraction Times of Different Fibre Bundles in the Brachial Biceps and Triceps Muscles of Man}

MUSCLE fibres differ histochemically and these differences are reflected in the susceptibility of the fibres to disease ${ }^{1}$. In animals, histochemical types have been related to the speed of contraction ${ }^{2,3}$. Hitherto this has not been possible for the different fibre types within a human muscle.

The development of semiconductor strain gauges has made it possible to construct a transducer by which twitch responses of a small group of fibres can be recorded. This strain gauge has high sensitivity and is so small that it can be mounted in a cannula $0.6 \mathrm{~mm}$ in diameter.

The tip of the cannula was inserted into the tendon of different muscles and the strain gauge recorded the displacement of the tendon during near-isometric twitches. The suitability of the method was tested by recording twitches evoked in the adductor pollicis brevis muscle by stimulating the ulnar nerve. The responses shown by the strain gauge and by conventional procedures ${ }^{4}$ were recorded simultaneously. Whether the stimulus activated 5 per cent or all of the muscle fibres, the time to the peak of the twitch (contraction time) by the two procedures usually did not differ more than $2 \mathrm{~ms}$. The static sensitivity and the frequency response of the strain gauge allowed the force during a twitch to be reproduced with negligible distortion.

To activate different fibre groups within a muscle a stimulating cathode was placed in different regions of the end-plate zone. Twitches of two fibre groups in the brachial triceps and biceps muscles are shown in Fig. 1. Contraction times exceeding $60 \mathrm{~ms}$ occurred in 30 per cent of fibre bundles of the brachial biceps and in 2 per cent of the bundles of the brachial triceps $(P>0.001$, Fig. 2). This corresponds to the histochemical and electronmicroscopical findings (unpublished work of H.S.) that $25+3$ per cent of the fibres in the long head of the brachial biceps were rich in mitochondria and were stained intensely by sudan black B, whereas this typo of fibre was rare in the lateral head of the brachial triceps muscle $(2 \pm 1$ per cent, fourteen subjects, $7-79 \mathrm{yr}$ old).

Twitch responses in single motor units activated during weak voluntary effort have been recorded in the brachial biceps muscle of three subjects by electronic averaging. The motor units recruited first had long contraction times within the range of the histogram of Fig. 2. Fasciculations of normal muscle were faster and had a higher amplitude than the twitch responses of weak effort.

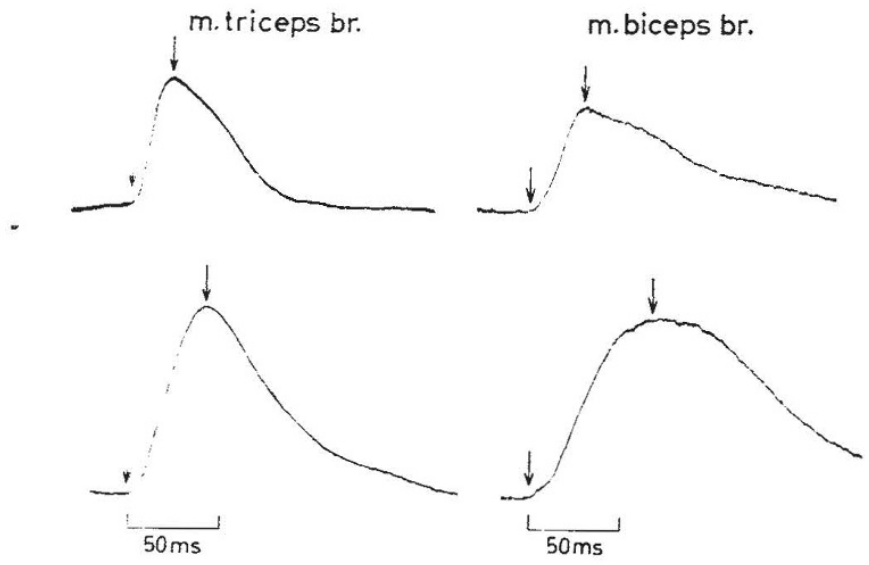

Fig. 1. Twitches with different contraction times in two fibre bundles of brachial triceps (left, subject S. H., 18 yr old) and brachial biceps (right, subject C. M., 16 yr old; intramuscular temperatures $36 \cdot 5^{\circ} \mathrm{C}$.
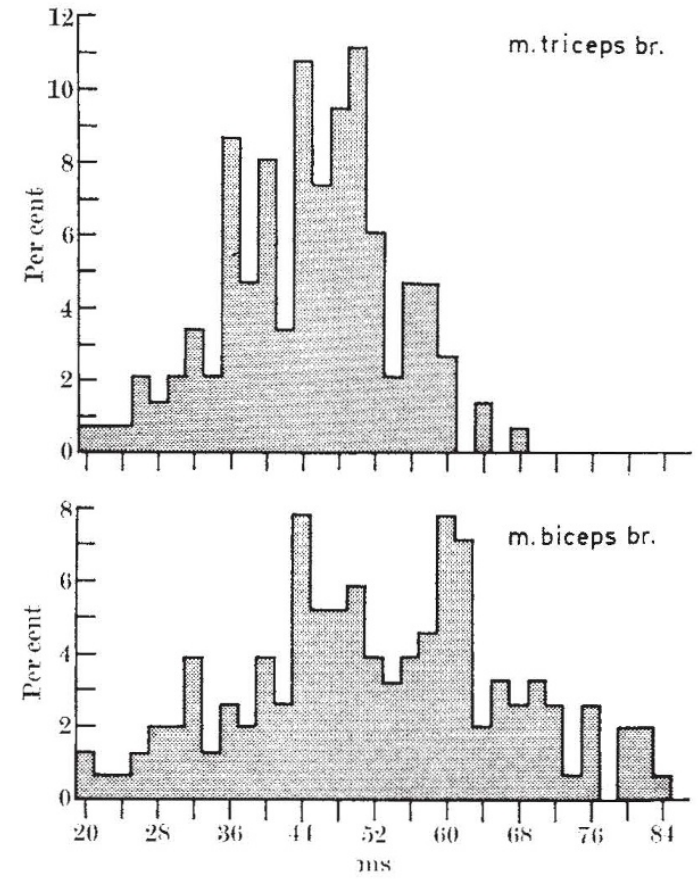
Fig. 2. Histogram of contraction times in 154 fibre bundles of the
brachial biceps and in 148 fibre bundles of the brachial triceps $\left(36.5^{\circ} \mathrm{C}\right.$, sixteen subjects, 16-63 yr old).

The spectrum of contraction times in other normal muscles and in neuromuscular disease will be described elsewhere.

We thank $\mathrm{Mr}$ Emme for mounting the semiconductor strain gauges in the cannula, and both he and $\mathrm{Mr}$ Ousager Andersen for advice. This work was supported by grants from the Muscular Dystrophy Associations of America, the Danish National Association for Infantile Paralysis and the Ernst Poensgen-Stiftung Dusseldorf.

F. BUCHTHAL

Institute of Neurophysiology,

H. SchmalbruCH*

University of Copenhagen.

Received December 16, 1968.

*On leave of absence, Inst. f. Biophysik und Elektronenmikroskopie, Universitāt Düsseldorf, Germany.

${ }_{1}$ Dubowitz, V., Developing and Diseased Muscle (Spast. Internat. Med. Publ. Heinemann Med. Books, Ltd, 1968).

${ }^{2}$ Cooper, S., and Eccles, J. C., J. Physiol., 69, 377 (1930).

${ }^{3}$ Hennemann, E., and Olson, C. B., J. Neurophysiol., 28, 581 (1965).

'Slomic, A., Rosenfalck, A., and Buchthal, F., Brain Research, 10, special issue (1968).

\section{Virus-like Particles in Penicillin producing Strains of Penicillium chrysogenum}

UNTIL quite recently the edible mushroom viruses ${ }^{1}$ were the only viruses known to infect fungi. During the past $2 \mathrm{yr}$, however, virus-like particles with interferon stimulating properties have been described in strains of Penicillium stoloniferum $^{2-5}$ and Penicillium funiculosum ${ }^{4}$. We have screened various fungi for possible viral content as part of our research programme relating to fungal viruses and interferon stimulation. Following reports of anti-viral and interferon stimulating agents isolated from Penicillium chrysogenum (ref. 6 and personal communication from P. Van Dijck, E. De Clereq, C. Cocito and P. De Sorner), we have examined various strains of this fungus for virus content. Virus-like particles have been found in seven penicillin producing strains of $P$. chrysogenum: NRRI, 1951, NRRL 1951 B.25, X.1612, Q.176, Wis. 48-701, 